\title{
EUROPE 2020 AND LIFELONG LEARNING
}

POR FIORELLA PEROTTO

Subdirectora de la Unidad Educación y Formación en Europa 2020. DGEC. COMISIÓN EUROPEA

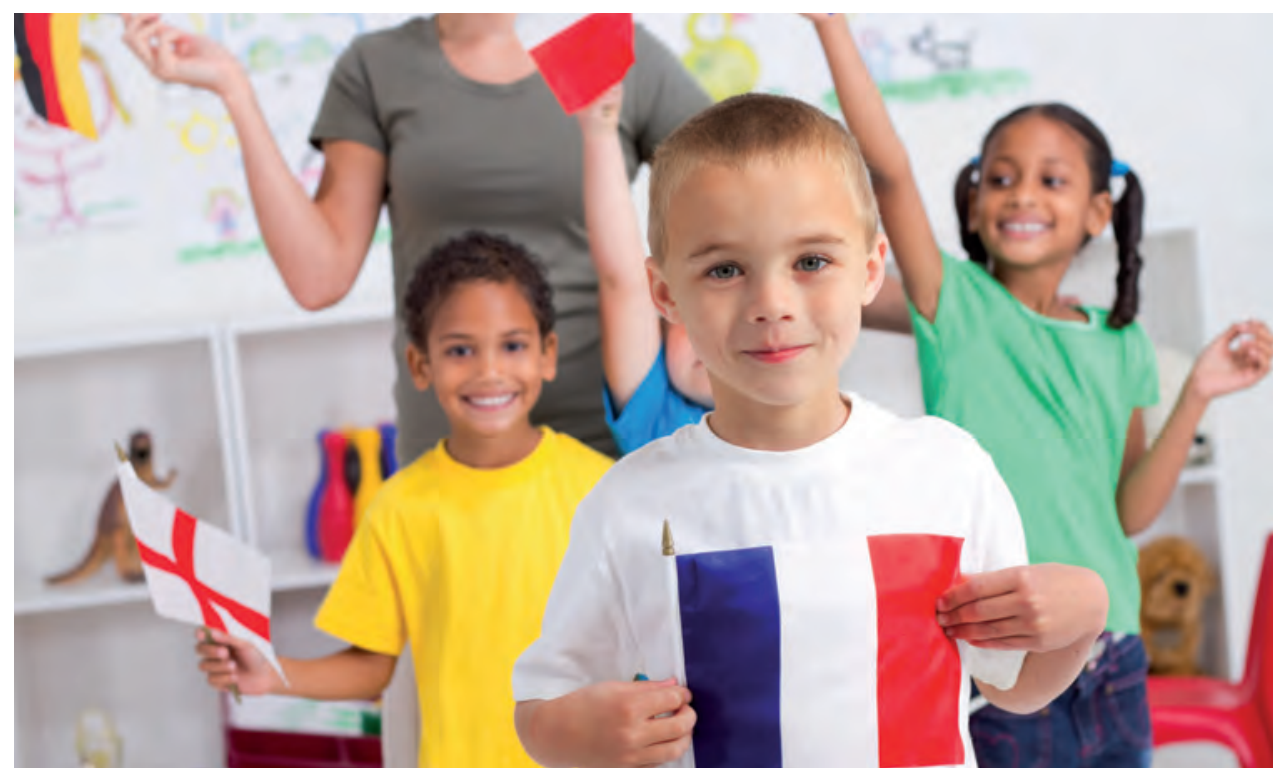

Lifelong Learning is part of the Europe 2020 strategy of the European Union. Despite the financial and budgetary pressures as well as the bleak employment forecasts in the member states of the European Union, it is essential and urgent to strengthen Lifelong Learning, education and training. The European Union is ready to help its member states to pursue this ambitious goal. 
Young people first need to acquire basic general skills to prevent them from becoming vulnerable low-skilled workers. They also need to learn technical or academic skills which are more job-specific, both general and specialised skills are necessary

The Europe 2020 strategy was launched in 2010 by the European Union as a reaction to the economic and financial crisis that affected millions of individuals in most European countries and economic sectors. The first aim of this strategy was to deal with the most urgent challenges linked to the crisis, in particular unemployment: millions of low-skilled jobs disappeared during the crisis, youth unemployment reached $20 \%$ on average at European level but in fact much higher levels in some countries -where it even doubled, such as in Spain. Another objective of Europe 2020 was to support the forecasting of skills needs and the need to match future skills needs with the requirements of the labour market. This basically means re-skilling and up-skilling adults or older workers in order to facilitate their conversion to different sectors.

Another important aim of the Europe 2020 strategy, however, is to prepare the European Union for the future: to support the recovery from the economic and financial crisis and enhance economic growth. There are also some other challenges which we need to deal with. To prepare for economic growth we should for example take into account that the request for high-skilled jobs will increase while the request for low-skilled jobs will diminish by 2020 . By $2020,35 \%$ of all jobs will require high level qualifications. The crisis and demographic developments (the size of the working population of the European Union is starting to shrink) mean that Europeans will have longer working lives. We therefore need to increase participation in Lifelong Learning. However, participation of adults in Lifelong Learning decreased between 2005 and 2010. We also need to anticipate future challenges.

Unemployment is particularly high among the low-skilled, older workers, but also young people, many of who leave school too early, especially in Spain. Unemployment is also increasing among university graduates. Knowledge, skills and educational qualifications are important, but they must be relevant and adequate.

The low-skilled were the first to be laid off during the crisis; those who managed to keep a job run the highest risk of unemployment. Therefore it is essential that they improve their skills and educational qualifications.

Young people also paid a very high toll due to the crisis - particularly in Spain but also in other countries. We need to help young people to find a job in the future by providing them with the right skills and qualifications from the start.

Early school leaving is a major challenge in Europe, Spain in particular. Although Spain has made considerable progress in reducing the rates, more can be done.

Young people first need to acquire basic general skills to prevent them from becoming vulnerable low-skilled workers. They also need to learn technical or academic skills which are more job-specific, both general and specialised skills are necessary.

The labour market is changing. Along with a reduced demand for low-level qualifications and an increased demand for specialisation there is also an increasing demand for flexibility among the workforce. Education and training are a long-term investment; young people need time to ac- 
Planned development of the labour market and of low-skilled, medium-skilled and high-skilled jobs until 2020

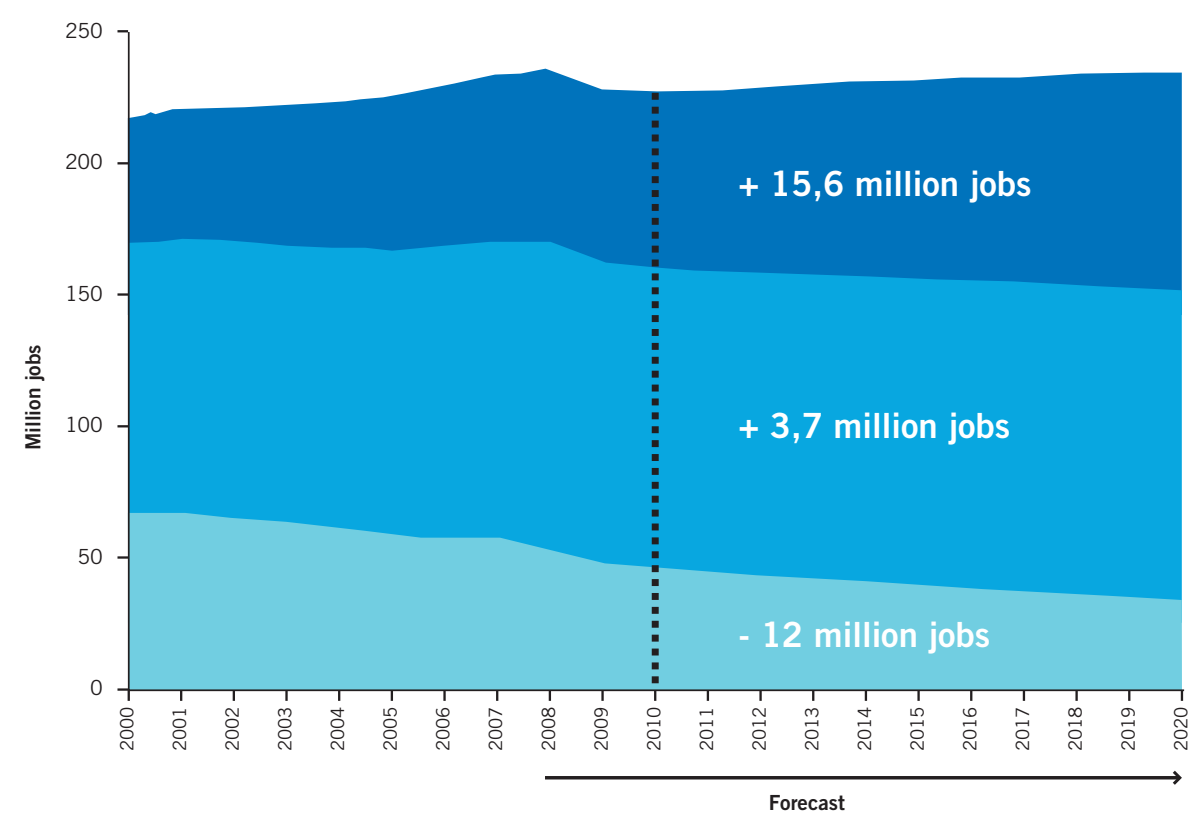

Low qualifications

Medium qualifications

High qualifications

Source: Cedefop, 2010.

quire the necessary skills and to practise them. Therefore it is urgent to start working now.

Despite generally high unemployment levels, certain employers are encountering difficulties in finding qualified staff. There is also a need to encourage people not necessarily to be employees but to take the initiative and become entrepreneurs.

There are currently mismatches between the skills and competences required on the labour market and those delivered by the educational and training systems. Such mismatches are one of the significant factors which have an impact on unemployment in certain sectors and on youth unemployment in general.

There is a need to help EU Member States to modernise their education and trai- ning system in order to better respond to the requirements of the labour market, and to do this in partnership with employers and with all the other relevant stakeholders.

\section{The role of Lifelong Learning in the context of Europe 2020}

The concept of Lifelong Learning has a long history. In the European Union, the concept of Lifelong Learning was introduced around the year 2000, with a communication by the European Commission. In 2002, in a communication from the European Council of Ministers for Education, EU Member States committed themselves to setting up coherent and comprehensive strategies for Lifelong Learning. Such stra- 
tegies were to be based on a set of priorities which were to be the main building blocks for consistent, coherent and comprehensive Lifelong Learning strategies in the EU Member States: the validation and recognition of learning outcomes, information and guidance, investment and resources, basic skills and innovative pedagogy.

The 2012 Joint Report on the implementation of the

European framework for cooperation in education and training (ET 2020) - findings on Lifelong Learning

Early in 2012 the European Commission and the Council of European Ministers for Education adopted a Joint Report on the implementation of the European framework for cooperation in education and training -the so-called "ET 2020" strategic framework- which devotes one full chapter to lifelong learning and to the implementation of Lifelong Learning strategies.

The main findings of this report show that comprehensive Lifelong Learning strategies exist only in a few EU Member States. Nevertheless, the Lifelong Learning approach is reflected in the education and training policies of most countries -although it does not necessarily carry a "strategy" label. Some progress has indeed been made in most European countries, especially as regards the so-called "transparency tools": the National Qualification Frameworks, guidance and coordination between different sectors as well as on the validation of non-formal and informal learning outcomes. However, more remains to be done.
For example, learning in the workplace is still too limited. The financing opportunities and incentives are not sufficient or not sufficiently effective, and there is still a lot of fragmentation or segmentation between sectors. Communication and coordination are also still comparatively weak. Learners from disadvantaged social economic backgrounds do not receive all the support and the incentives that they would need. Guidance and counselling are not sufficiently developed. In summary, the holistic policy approach that was advocated a decade ago is not a reality except in very few Member States: Austria, Cyprus, Denmark, Slovenia and the United Kingdom. Many countries have introduced European and national qualification frameworks and mechanisms to validate the outcomes of non-formal and informal learning and Lifelong Learning guidance policies. This shows that barriers for cooperation between education sectors can be overcome. However the majority of countries do not yet look at life-long learning from a strategic perspective. In national and regional administrations, Lifelong Learning strategies often still focus on the skill development of the current workforce in particular sectors, rather than on structural reforms for providing the entire population (not only the working population) with the right competencies, thus providing the opportunity to self-direct learning throughout life in a sustainable way. Most countries are increasingly aware of the need for education and training systems to interact with the labour market and social policies. Many countries are introducing reforms in areas which are important building blocks for Lifelong Learning. These reforms relate to early childhood education and care, or to 
reducing the number of early school leavers, introducing flexible learning pathways and implementing European transparency tools or others enabling the recognition, for example, of skills and competencies in vocational and educational training.

Despite all these efforts, however, participation of adults in Lifelong Learning has continued to decrease. This demonstrates that the impact of Lifelong Learning policies on individuals is rather weak, and opportunities are not sufficiently adapted to the needs of the target groups. Incentives for education providers are not always sufficiently developed.

There is also insufficient effort to promote flexible learning pathways among potential target groups. Life-long learning takes place extensively outside the formal education and training system, in both a "life-long" and "life-wide" perspective. Learning opportunities outside the formal systems that are available in civil society or in the workplace are not sufficiently valued or stimulated. Although the introduction and development of national qualification frameworks is progressing, in some countries it is limited to certain levels of qualifications, especially higher levels which are rewarded with academic or vocational qualifications by higher education institutions. This often restricts the flexibility of learning pathways.

Life-long guidance is also becoming increasingly important in European countries. Many countries are working on tools to validate non-formal and informal learning. However, there are significant differences in progress between the different countries. Some have been trying to introduce reforms to remove barriers at institutional level, for example by encouraging the opening up of higher education institutions of universities to so-called "non-traditional" or "underrepresented" groups of learners, in particular by adapting their educational provisions.

Some countries have pinpointed the at- tractiveness of vocational education and training as an important priority of Lifelong Learning policies and have introduced initiatives aiming, for example, at stimulating the provision of apprenticeships and the creation of apprenticeship places in companies.

Many countries are aware of the importance of better targeting the continuing training for adults and in particular of the lowskilled, the unemployed, older workers and older people in general, and for migrants. Another element which is pinpointed in a number of countries is quality assurance in education and training, which significantly complements the Lifelong Learning policy.

Lifelong Learning in the

context of the Europe 2020 strategy

- The Europe 2020 targets

Europe 2020 is a wide socio-economic strategy that pursues smart, sustainable and inclusive growth. It explicitly acknowledges the role of Lifelong Learning and skills development as key elements to respond to the economic crisis and to pave the way for future growth. Europe 2020 does not only rely on broad strategic goals, but also on quantitative targets. One of them focuses on education, training and aims -on the one hand reducing the rate of early school leavers at European level to less than 10\% by 2020 (the current European average is a little over $14 \%$ ) and on the other hand increasing tertiary education attainment or equivalent to at least $40 \%$ by 2020 (the European average is $33.6 \%$ ). So these targets can be measured and monitored through indicators.

The European headline targets have been translated into national targets: each country has set its own national target in relation to the European targets, which takes into account the starting points of the di- 
The Europe 2020 strategy is accompanied by guidelines providing concrete implementation directions for Member States especially to improve employment and the economic situation

fferent countries, their policy priorities and the capacities of the education system.

- Spain has set a target to reduce the early school leaving rate to $15 \%$ by 2020 (the current rate is over $28 \%$ ), with an intermediate national target of $23 \%$ by midterm (2015). As regards tertiary attainment, Spain has already exceeded the European target of $40 \%$. The Spanish level is currently $40.6 \%$ and the national target for Spain is $44 \%$ by 2020 , with an intermediate target of $41 \%$ by midterm (2015). (Taken from The Europe 2020 Employment Guidelines )

The Europe 2020 strategy is accompanied by guidelines providing concrete implementation directions for Member States especially to improve employment and the economic situation. Integrated guidelines on Employment no. 8 and 9 focus on education and training, and on Lifelong Learning. Guideline $n^{\circ} .8$ states the need to promote Lifelong Learning to develop a skilled workforce that responds to labour market needs.

Guideline $n^{\circ} .9$ focuses on the quality and performance of education and training systems at all levels. It also focuses on the need to increase participation in tertiary education, which is also linked to Lifelong Learning, since increased participation in tertiary education is expected to foster attainment. These two guidelines, together with the headline targets, are the legal basis for action in education and training in the framework of the Europe 2020 strategy. They justify the key role of education, training and Lifelong Learning in the implementation of Europe 2020.

To support progress towards the headline targets in education and training, the European Commission has launched a number of so-called flagship initiatives.

The first flagship initiative is Youth on the Move. It targets young people and its main objectives are to tackle the issue of early school leaving and youth unemployment, and to ensure higher skill levels by making education and training more attractive. This will in turn encourage young people to stay longer in education and training as well as making education and training more relevant to the needs of the labour market, by including high-quality vocational education and training. Youth on the Move also aims at supporting the achievement of the tertiary attainment target and to encourage higher education institutions to become more open to Lifelong Learning. Other policy initiatives are more sector specific, for example the Bruges Communiqué and the Copenhagen process for the improvement of vocational education and training or the Council recommendation on reducing early school leaving, and the communication on the modernisation of higher education which were adopted in 2011.

Another flagship initiative which is particularly relevant to Lifelong Learning is the "Agenda for new skills and jobs" which pursues two objectives. The first concerns active labour market policies: creating jobs, improving the quality of work and working conditions, ensuring a better operation of the European labour markets, flexicurity, strengthening the life-long learning pillar. The second objective focuses on improving skills forecasting and skills matching, and on the need to provide the right skills both for today and tomorrow's jobs labour market. 
Under "skills" we mean general basic skills, transversal competences (the so-called "soft skills") and job-specific skills. The Agenda for new skills and jobs aims at supporting educational and career guidance and at fostering partnerships between education and training and the world of work. The Agenda does not focus on young people specifically, but promotes actions which are intended for groups who are more vulnerable in the labour market, such as low-skilled people, older workers, or migrants with low social economic backgrounds, but also young people, who may lack experience or the right skills. The Agenda for new skills and jobs also aims at improving skills levels through other initiatives. Here are a few examples: a high-level group of experts on literacy, set up in 2011; a policy network on the education of migrants and a renewed agenda for adult learning, adopted by the

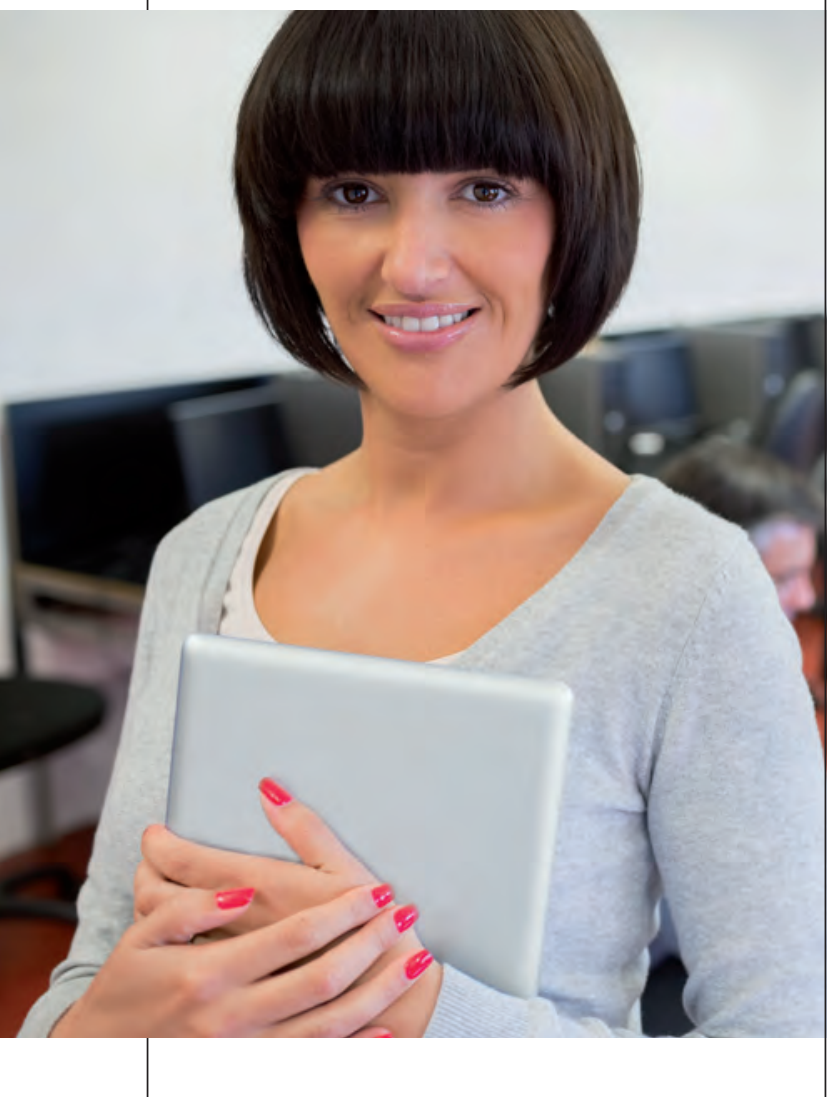

Council of Education Ministers to renew the previous Action Plan for adult learning. Finally, a new Communication on skills and qualifications is planned for the end of 2012, because the need to improve skills does not only concern job-related skills, but also general skills, which are important not only for employment but for citizenship and personal development.

The agenda for new skills and jobs supports initiatives to strengthen the links between Lifelong Learning and the labour market. One of them is the Skills Panorama, which should be completed by the end of 2012, on the anticipation of skills needs for job seekers and for employers. Another is European Skills Passport, to help citizens to make their skills and competences more visible, to facilitate recognition and validation, and finally the ESCO (European Skills, Competences and Occupations) taxonomy: a kind of common language for the definition of skills, competences and occupations. We must also mention the Knowledge Alliances between education -in particular higher education- and business.

The Agenda for new skills and jobs also announced the adoption of a proposal for a Council recommendation on the validation of non-formal and informal learning. It was to be adopted in 2011 but due to some delay it will be adopted in 2012. It also fosters the implementation of the National Qualification Frameworks and its referencing to the European Qualification Framework in order to increase the transparency, understanding and recognition of qualifications within different countries and so provide Member States with a common grid on qualifications. This aspect is particularly relevant to reinforce transparency and facilitate recognition and validation of learning outcomes, the mobility of learners and teachers and the mobility of workers across countries. It is also important to mention here the European Credit System for Vocational Education and Training and the 
The Lisbon "Europe 2010" process had a global approach -with benchmarks and indicators at national level but no targets or recommendations addressed to individual Member States

financial support for policy development in the area of Lifelong Learning provided through the current EU Lifelong Learning Programme.

Europe 2020 is a strategy that stretches over a decade, until 2020. However, Europe 2020 is a combination of long-term and short-term strategies, as it operates through an annual monitoring process. Every year, progress of the Member States towards the decade's targets is reviewed at European level. Another distinctive feature of Europe 2020 is a country-specific approach. This is a major difference compared to, for example, the previous "Lisbon" process. The Lisbon "Europe 2010" process had a global approach -with benchmarks and indicators at national level but no targets or recommendations addressed to individual Member States. Europe 2020 is rather different in this respect. The process of an annual review in Europe 2020 is the so-called "European Semester", which allows for better focus, thus increasing the chances of reaching the strategic goals of Europe 2020. Furthermore, the country-specific approach creates stronger ownership among the Member States for the Europe 2020 strategy. In the first half of each year (the European Semester), Member States coordinate their economic policies at European level. They set trajectories allowing them to monitor each step towards the ultimate goals and to rectifications if necessary. Member States identify short-term annual challenges as part of the trajectory and submit National Reform Programmes to the Commission. The Commission analyses these Programmes, which also cover life-long learning, education and training. The Commission then provides Member States with both guidance and recommendations to help them focus on the right priorities to reach the Europe 2020 goals. The second half of the year is the "National Semester", when Member States transfer the European recommendations into national reforms and measures that are then integrated into the process for the preparation of national budgets for the following year. During the first European Semester in 2011, the Council issued country-specific recommendations on education, training and Lifelong Learning to 16 Member States. Overall, twelve recommendations to Member States focused on Lifelong Learning, vocational and education skills, and the active labour market policy dimension. Five recommendations focused on early school leaving, five on tertiary education (ten overall on the education headline target). Three recommendations concerned pre-school education, again linked to Lifelong Learning, and one on the quality and performance of school education. Spain received two recommendations in 2011: one on Lifelong Learning and one on early school leaving. The first one stated that Spain is to develop further measures to improve Lifelong Learning for older workers. The second one requires Spain to closely monitor the effectiveness of the measures set out in the 2011 National Reform Programme to reduce early school leaving, through prevention policies, and facilitate the transition to vocational education and training. It is generally recognised that Spain has already adopted a number of important measures, especially to compensate early school leaving, through counselling or by facilitating the reintegration of 
dropouts. This is in compliance with the Council's recommendation, but the efficiency of these measures should be carefully monitored, and more research should be done to: 1) identify the groups at risk of early school leaving, and 2) pinpoint the regions where the situation is more difficult, since there are major differences between the autonomic communities in Spain as regards early school leaving. According to the 2011 recommendation, all these aspects should be improved.

The closure of the second European Semester is now approaching and the Commission is finalising the analysis of the 2012 National Reform Programmes. I would now like to mention the Youth Opportunities Initiative, which is another element of Europe 2020 and also has a Lifelong Learning component. The European Semester 2012 actually did not start on the $1^{\text {st }}$ January 2012, but in November 2011 with the adoption of the Annual Growth Survey by the European Commission. The Annual Growth Survey is a policy document which reviews the general progress towards the Europe 2020 goals and delivers key policy messages which the Member States will have to take into account when drawing up their National Reform Programmes and prioritising their policy decisions and objectives. One of the key messages in the 2012 Annual Growth Survey was a call to Member States to preserve and, if possible, to prioritise expenditure -despite tough fiscal consolidation measures- in growthenhancing sectors such as education and research and to ensure the efficiency of such spending. This focus on the longer-term was a significant step since in 2011 the key messages of the Annual Growth Survey focused on short-term measures to deal with the immediate needs resulting from the crisis. In 2012 the focus is not only on immediate short-term measures but on structural reforms. Why is this?

Because the lower-skilled stand a high

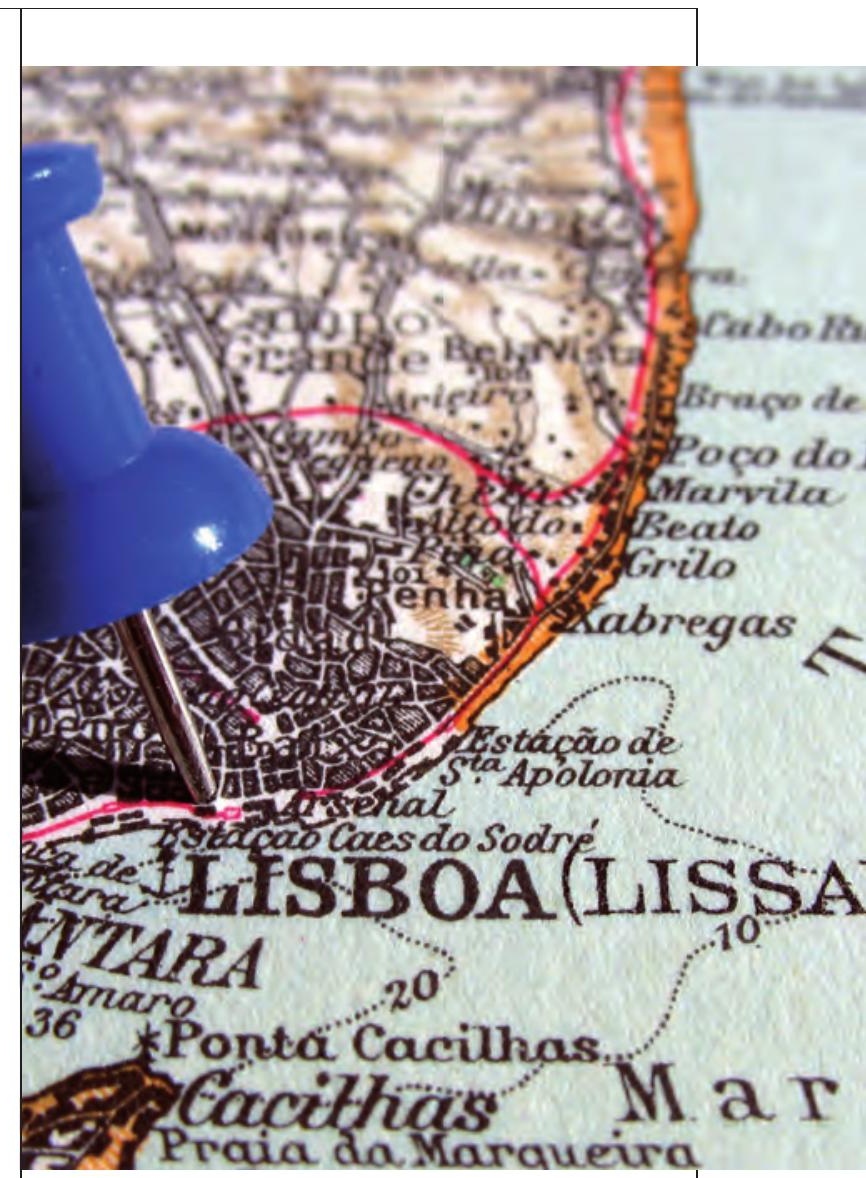

risk of unemployment and are the first ones to be laid off in times of crisis. Because large numbers of young people are unemployed, we need to start training them now so as to be ready when the recession ends and growth picks up again. There is a need to reduce and prevent skills mismatches since, despite high unemployment, there are pockets with a high demand for qualified workers, which cannot be met by education and training systems. This is therefore leading to an increase in the demand for medium or high-skilled qualifications.

Youth unemployment was very much centre stage both in the 2011 European Semester and in the 2012 Annual Growth Survey. Youth unemployment is very high in a large number of European countries -especially Spain. Therefore it was decided to launch 
In April 2012 the Member States submitted their National Reform Programmes for the following year to the Commission and reported on how they had implemented the stability and convergence programmes and the country-specific recommendations of 2011

a specific European initiative on youth unemployment. The" Youth Opportunities Initiative", presented by President Barroso. The Initiative has a strong country-specific dimension and focuses on a review of national policies and performances. It provides financial support both to national measures and cross-border initiatives and aims at encouraging Member States to establish a "youth guarantee" to ensure that young people are either in education or training, or find a job within four months of leaving school. The Youth Opportunities Initiative also emphasises the need to support apprenticeships, work placements and traineeships, to provide young people with practical experience, since young people often leave school with academic qualifications but no practical experience in the workplace. The idea is to use European Structural Funds, in particular the European Social Fund, to support work-based experience and learning through apprenticeships, placements in companies and traineeships, but also volunteer work -for example through the European Voluntary Service, since volunteer work is considered a very good way for young people to acquire practical experience and come into contact with the world of work for the first time. In the framework of the Youth Opportunities Initiative, the European Commission decided to take urgent action to support the eight Member States where youth unemployment was higher than $30 \%$. Spain is one of them. The Commission also launched targeted action for a group of a further seven countries who also have very high youth unemployment rates. Mr Barroso proposed Member States establish joint "youth action teams" including representatives both from the Commission and from national authorities: ministries of labour, of economy and education. The aim was to agree on the general lines for a "youth employment plan". The plan should include policy and budgetary measures; support for training young people and support for tackling skill mismatches, and for reducing early school leaving. In order to allow a larger number of young people to participate in European instruments, Mr Barroso suggested that these new measures could be funded by redirecting unallocated European Social Fund means, which are sometimes quite considerable. This could also help gain leverage from social partners and from private sources. The Action teams should also involve representatives from the central departments, businesses and employers and should act as catalysts to facilitate an increase in the number of apprenticeships and job placements. Another idea was to use unspent funds from the European Social Fund to fund additional learning mobility opportunities for young people (students and apprentices) in Europe through programmes such as Erasmus or Leonardo Da Vinci, under the Lifelong Learning programme. These opportunities provided by the EU would enable young people to acquire working experience abroad in a company.

Earlier this year, a delegation of the European Commission -including representatives from Directorate-General for Education and Culture- visited each of the eight priority target countries, including Spain. The outcomes of the Action Teams' work are currently being analysed and agreed upon by the Commission and the Member States concerned. However, certain trends 
are more or less common throughout the eight countries as regards the kind of priority measures that need to be adopted.

First, it is worth emphasising that the ministers responsible for education and training played a very prominent role in the discussions a national level within the Action Teams. This is very important and shows the key role of education in Europe 2020 and the importance of education and Lifelong Learning for the employability of young people.

Second, there was wide agreement on the need to reform education and training systems and on the importance of European instruments to support these reforms both in the short and longer term. When reforming education and training systems, there is a need to strengthen vocational education and training and to improve the apprenticeship system.

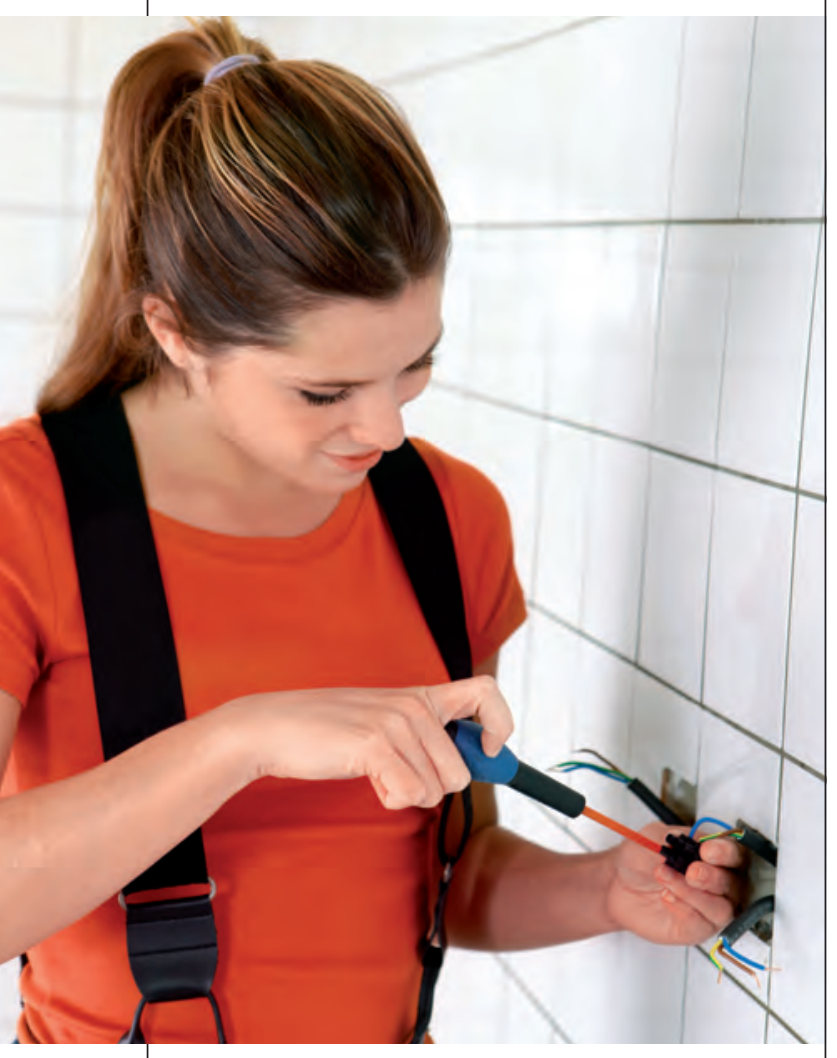

Third, early school leaving needs to be reduced, not only by reintegrating those who already dropped out, but also by preventing students from dropping out. Some countries are particularly interested in the possibility to redirect funds from the European Social Fund to fund European learning mobility for young people. Negotiations are on-going with the Member States and the National Agencies responsible for the implementation of the European Lifelong Learning programme to see how this can actually be carried out in practice because in many countries -Spain, for example- the demand for mobility grants under Erasmus or Leonardo da Vinci exceeds by far the supply available, so we observe a very strong interest among young people. Transnational learning mobility was highlighted in most Member States as an area for further priority funding. The final conclusions by the Teams on their work will be presented later this year, together with the results of the European Semester 2012.

In April 2012 the Member States submitted their National Reform Programmes for the following year to the Commission and reported on how they had implemented the stability and convergence programmes and the country-specific recommendations of 2011. Spain, for example, reported in its National Reform Programme how it had implemented the two recommendations on education and Lifelong Learning. National Reform Programmes are public documents and are available on the websites of the Member States' governments. They will also be available on the Commission's website.

The Commission is examining the 2012 National Reform Programmes and on the $30^{\text {th }}$ of May it will adopt the new countryspecific recommendations for 2012 and the so-called "May package" including an assessment of the progress made by the Member States towards the Europe 2020 objectives and headline targets as well as in implementing the 2011 recommendations. 


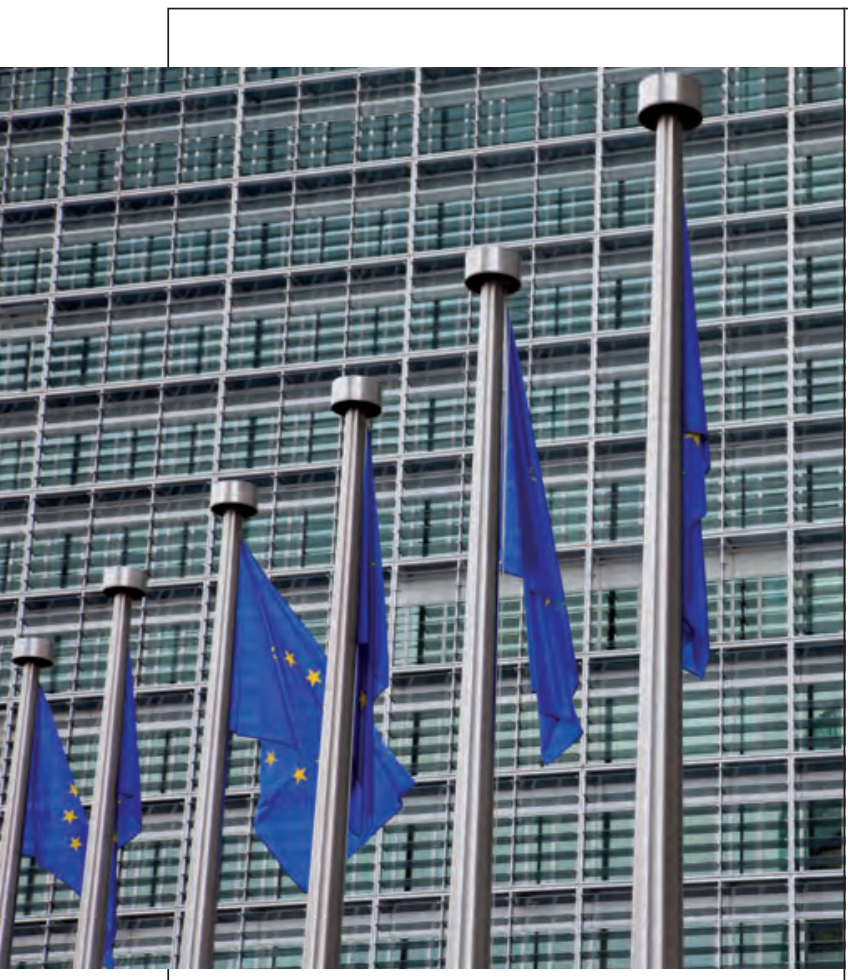

A set of Staff Working Documents (one per country) will provide a detailed analysis highlighting the new recommendations and also pinpointing other country-specific policy challenges.

The recommendations proposed by the Commission will first be adopted by the Economic and Financial ministers, by the Employment ministers and will then be endorsed by the European Heads of State and government in June/July.

Two new important features are worth mentioning, which also support Lifelong Learning. One is the multi-annual financial framework 2014-2020 (which is the funding instrument for European policy initiatives) and the European "Erasmus for All” programme. The European Commission has recently submitted a proposal for this new funding programme that would replace the current Lifelong Learning programme. The new programme will have a new name and, in part, a new scope. It will cover, not only education and training, but also youth and sport. It is also likely to enjoy a consistent increase in budget: more than $70 \%$. The new programme will simplify and streamline the current action of the Lifelong Learning Programme to take new developments into account, and blur the distinction between formal, non-formal and informal learning. It will focus on three main groups of actions: individual mobility of learners and teachers, cross-border partnerships and support of a policy reform.

The second element is the new regulation on structural funds for the next decade, where Lifelong Learning is a clear priority, in particular for the European Social Fund. The new element here is that there will be a clear conditioning between policy action and funding. Once the new regulation is adopted, Member States will have to demonstrate that there is a clear link between their national programmes, the Europe 2020 objectives and the country specific recommendations in order to receive financial support from the European Social Fund. If this is not the case, funding may be withdrawn. Linking funding to policy would ensure better consistency and stronger commitment.

The European framework for cooperation in education and training (ET 2020) is fully in line with the Europe 2020 objectives and will be used extensively. The ET 2020 instruments are being reviewed so that they better match the objectives of Europe 2020. For example, there will be new forms of peer learning between Member States, a European education and training "monitor" every year, showing key data on the indicators and benchmarks towards the objectives of Europe 2020. At the end of 2012, the Commission will organise a major European education and training Forum to discuss how Member States can deal with the priorities of Europe 2020 and the country-specific recommendations, including through cooperation with other international organisations. 